\title{
LEVANTAMIENTO DE LA CATEDRAL DE BURGOS
}

Carlos Clemente San Román, Arquitecto

E. A.: Av. Herrera Oria, 167. Madrid-ESPAÑA

Jesús Cantera Montenegro, Prof. de la Universidad Complutense

Ficha técnica: Catedral de Burgos

Dimensiones: Longitud total del conjunto catedralicio

$124 \mathrm{~m}$.

Ancho

$99 \mathrm{~m}$.

Superficie construida total en planta

$12.276 \mathrm{~m}^{2}$

Superficie del patio claustrado

$709,0 \mathrm{~m}^{2}$

Superficie de terrazas

$1.158,0 \mathrm{~m}^{2}$

Altura torres de fachada (pináculos) ............................................ $\quad 112,0 \mathrm{~m}$.

Altura cimborrio (interior)

$43,0 \mathrm{~m}$.

Altura cimborrio (exterior)

$59,0 \mathrm{~m}$.

\section{Cronología constructiva}

S. XI 1077.XII - Edificándose Catedral románica.

1096 - Finalización Catedral románica.

S. XIII 1221-20 julio - Se instala la primera piedra de la Catedral gótica (Obispo D. Mauricio y S. Fernando).

1230

- Se está finalizando la construcción de la Capilla de San Nicolás brazo norte del crucero.

1240 aprox. - Portada del Sacramental.

1250 aprox. - Maestro Enrique se hace cargo de las obras.

final siglo $\quad-$ Claustro actual.

S. XV principios - Se finaliza la Catedral y Claustro.

1442-58 - Juán de Colonia: torres.

S. XVI 1519-25 - Diego de Siloé: escalera dorada.

1576 - Juán de Vallejo: se finaliza el cimborrio actual.

S. XVII 1642 - J. Gómez de Mora: consolidación del cimborrio.

S. XIX 1887 a $\quad-$ Vicente Lampérez y Romea: Restauración de la Catedral y claustro. principios

del siglo XX

1927

- Consolidación agujas de la torre. 


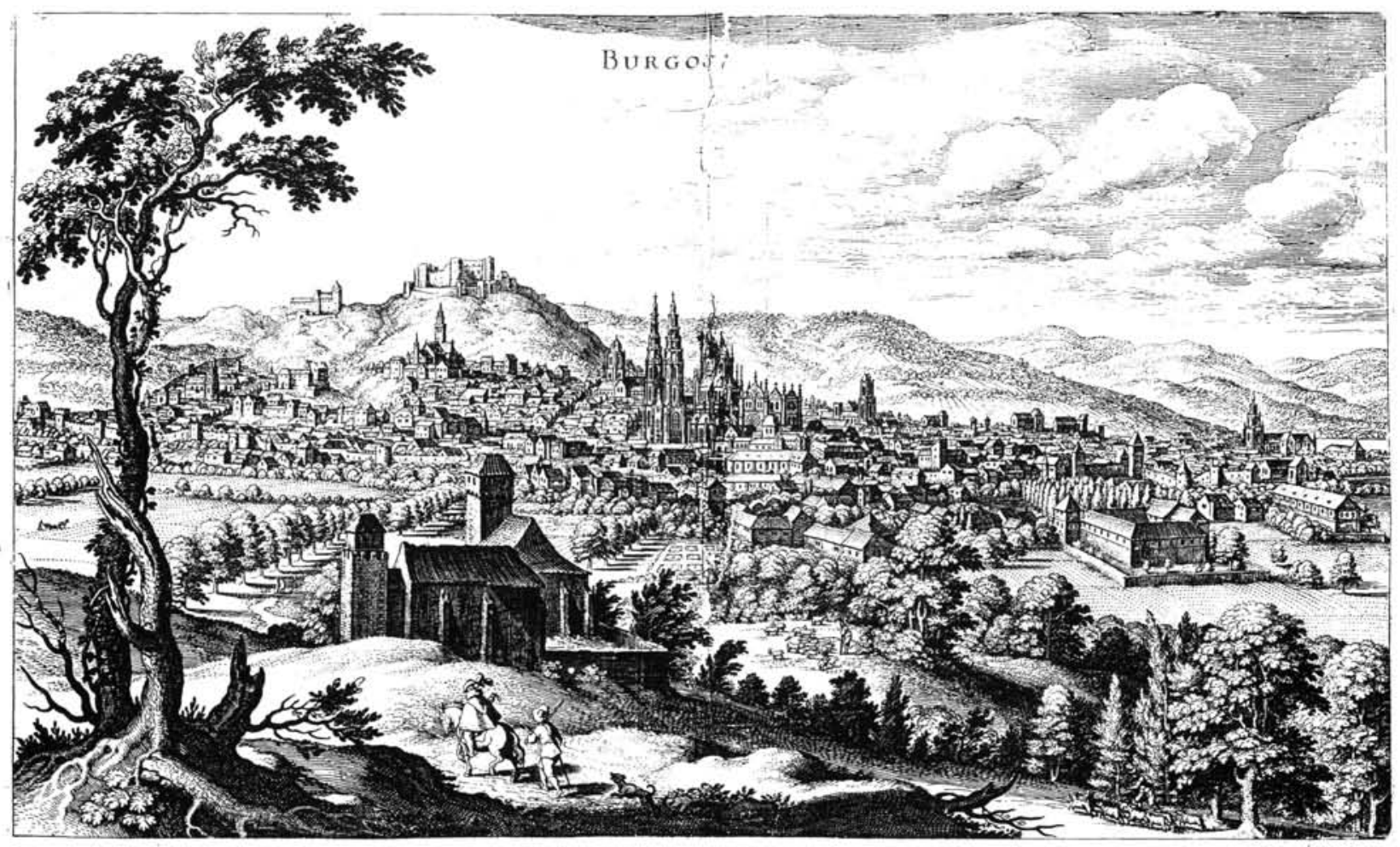

Grabado del Siglo XVI.

\section{Planimetria de la Catedral de Burgos}

La planimetria de la Catedral de Burgos tiene sus precedentes en las plantas generales realizadas a principios de siglo por dos arquitectos: don Vicente Lampérez y Romea y don Ricardo Velázquez Bosco. La planta de Lampérez, realizada con un criterio de geometrización basado en los postulados teóricos del neogótico, muestra unos ejes exactos con un orden riguroso en la proporción de naves, alturas y situación de los elementos constructivos. La planta y detalles constructivos de Velázquez Bosco continuan la trayectoria de este arquitecto en su interés por los comportamientos estructurales del monumento. Siendo importantes sus levantamientos y soluciones mediante estructuras metálicas roblonadas, es sin embargo la planta una geometrización en la que se omiten elementos y giros de gran interés para el comportamiento mecánico real del Monumento. Las restauraciones de las dos últimas décadas han dejado una importante documentación planimétrica sobre los detalles y zonas de conservación que serán de gran utilidad para la historiografia de esta Catedral. Son de destacar los alzados de portadas con fotogrametria realizados por el arquitecto José Sancho Roda y también los múltiples planos con soluciones de restauración dados por este arquitecto y el actual conservador, Marcos Rico.

Al realizar la planimetria general aqui publicada, los antecedentes más completos existentes fueron, por tan- to, aquellos levantamientos geometrizados del primer cuarto de siglo.

Encargado por el Ministerio de Cultura de 1981 a 1983 , para su posterior inclusión en el expediente de solicitud y declaración de esta Catedral como Monumento de la Humanidad, fue realizado este levantamiento por los arquitectos José Ramón Garcia Várques, José Ricardo Rodriguez Iglesias, Agustín Cabello y Carlos Clemente San Román. La supervisión del trabajo correspondió al arquitecto entonces inspector del monumen. to, José Sancho Roda.

El levantamiento realizado mediante teodolito y medios mecánicos en colaboración con el equipo de trabajo dimensional de la Universidad de Tubinga, tuvo un periodo de doce meses de toma de triangulaciones, giros y mediciones directas, que tomó mil doscientos cuarenta y dos bases o puntos de referencia. Estas fases fueron punto de partida para superponer los tres métodos de medición: teodolito, triangulación y dimen. sión directa. Sobre esta superposición se resolvieron un total de mil cuarenta bases. El resto fue determinado según el método considerado más exacto para ese punto. Las desviaciones no superaron, en ninguno de ellos, un margen mayor de diez centimetros.

Los documentos originales realizados a escala $1 / 50$, han finalizado en dos planos de planta de $6,24 \mathrm{~m}^{2} \mathrm{y}$ un plano de sección longitudinal de 3,5 × 2,05 m. Pa- 
ra llegar a estos planos se realizaron a E:1/20 todas las pilastras y pilares, incluyendo claustro y capillas.

Además de la planimetria del elemento estructural y arquitectónico, están levantados todos los objetos muebles y soluciones constructivas existentes: retablos, esculturas, vidrieras, rejas, escudos, escaleras, estructuras de cubiertas, solados y bóvedas. Consideramos esta integración importante para el conocimiento no sólo de los arriostramientos que estas estructu. ras muebles producen sino también del comportamiento global del monumento ante las posibles patologias: dilataciones estacionales o puntuales, relación química de los materiales y origen o paso de la zoología y microbiología de los materiales.

\section{Historia de la Catedral}

El origen de la sede burgalesa está en la de Oca, conocida ya en la segunda mitad del siglo VI, y que como tantas otras pasó duras penalidades durante la época de la dominación musulmana.

Cuando la situación política se fue estabilizando, y las tierras castellanas se vieron más seguras, el rey Fernando I decide que la sede ocupe un lugar más digno en virtud de su creciente importancia, decidiendo su traslado a la ciudad de Burgos, cosa que realizó definitivamente el rey Alfonso Vt ef día 1 de mayo de 1075 , quien cedió para la construcción de la Iglesia Catedral el solar del palacio real que habia en dicha población.

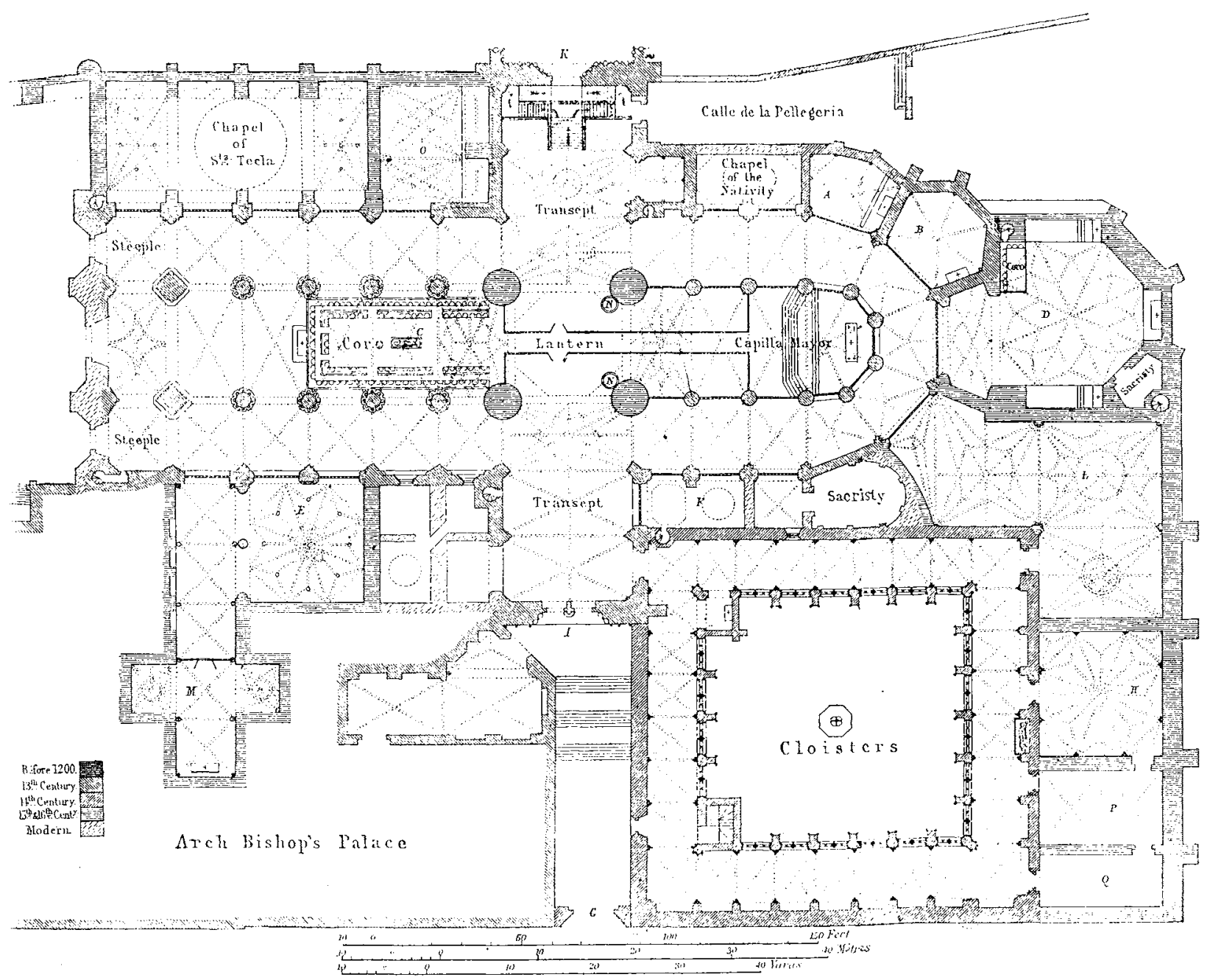

Planta de Street en la "Arquitectura Gótica en España"; 1865.

A) Capilla del Siglo XIV. B) Capilla de San Gregorio. C) Monumento sepulcral del arzobispo don Mauricio. D) Capilla del Condestable. E) Capilla de la Presentación. F) Capilla de San Enrique. G) Puerta del Sarmental. H) Capilla de Santa Catalina. I) Puerta del Perdón. K) Puerta de los Apóstoles. L) Capilla de Santiago. M) Capilla del Santisimo Cristo. N) Púlpitos. O) Capilla de Santa Ana. P) Estancia en la que se halla el "Cofre del Cid". Q) Salas capitulares.

Equivalencia castellana de los términos ingleses que aparecen en esta lámina:

Arch Bishop's Palace = Palacio arzobispal. Chapel of Santa Tecla = Capilla de Santa Tecla. Chapel of the Nativity $=$ CapiIla de la Natividad. Cloisters $=$ Claustros. Lantern = Cimborrio. Sacristy = Sacristia. Steeple = Campanario. Transept $=$ Brazo del crucero. Before $1200=$ Anterior a 1200. 13th Century $=$ Siglo XIII. 14th Century $=$ Siglo XIV. 15th \& 16th Century $=$ Siglos XV y XVI. Modern $=$ Moderno. Feet $=$ Pies. 


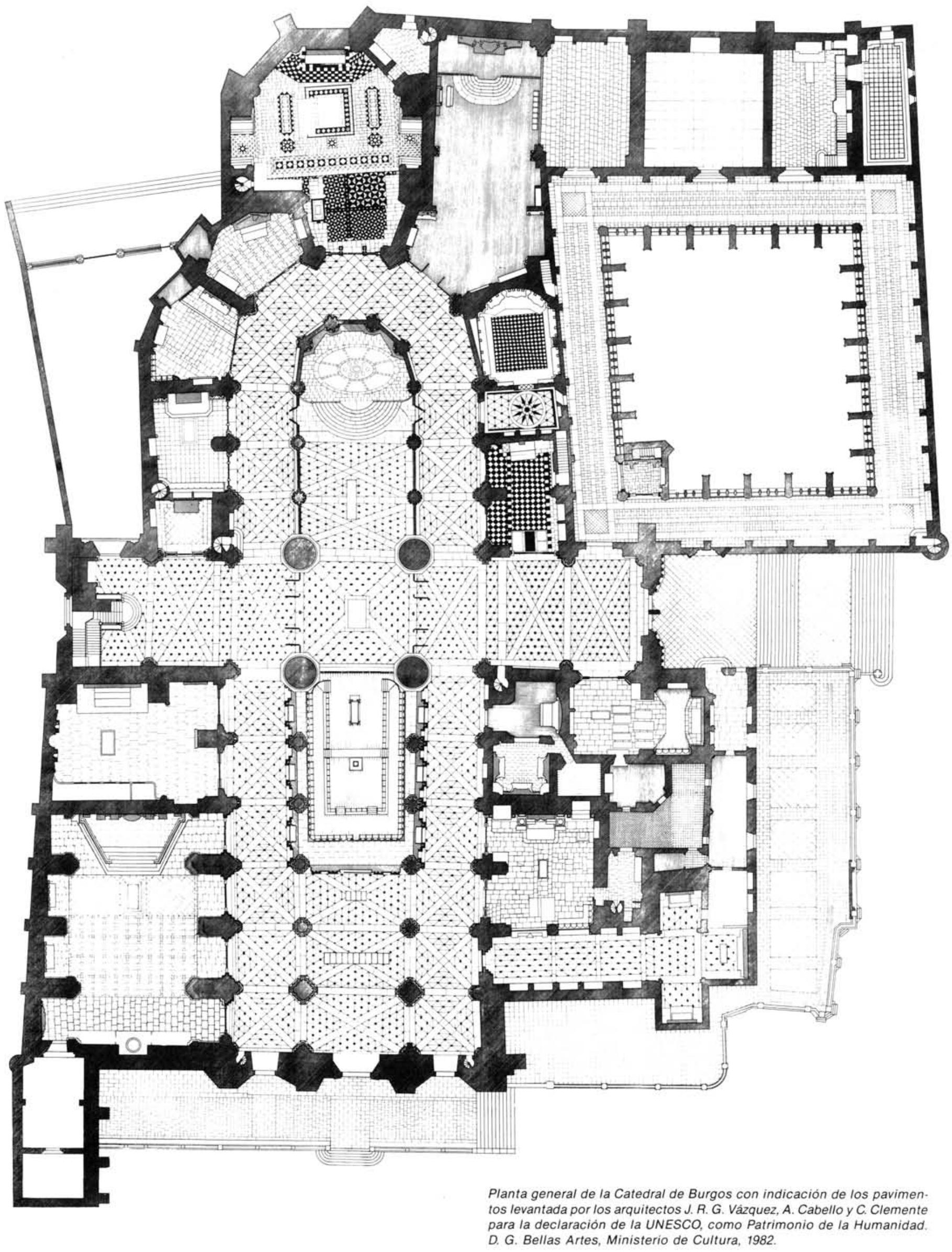




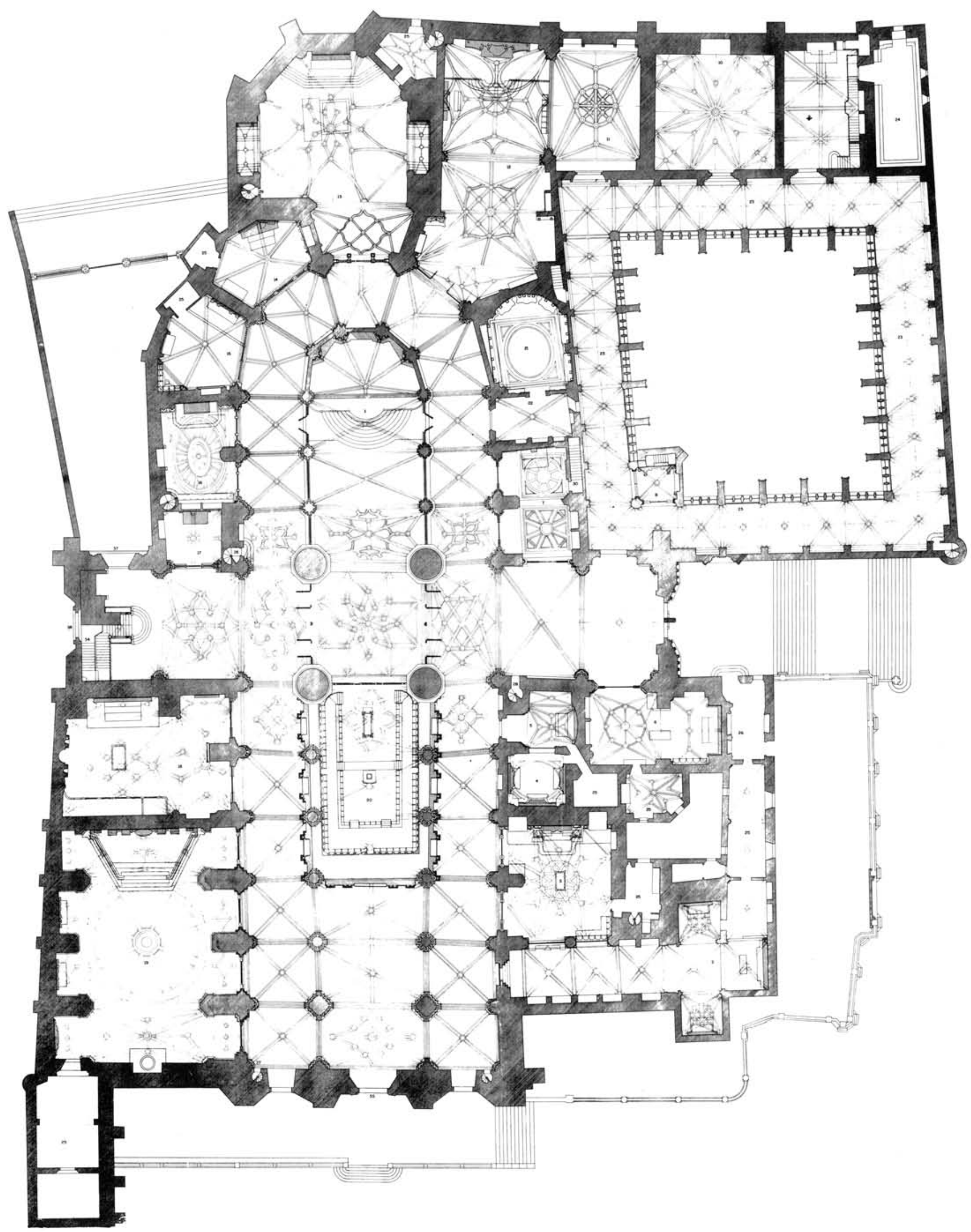

Planta de bóvedas de la Catedral de Burgos levantada por los arquitectos J. R. G. Vázquez, A. Cabello y C. Clemente para la declaración de Ia UNESCO, como Patrimonio de la Humanidad. D. G. Bellas Artes, Ministerio de Cultura, 1982. 
Inmediatamente se comenzó la construcción del edificio a costa del propio monarca, debiendo de haber quedado terminado antes de finales del siglo. Ocupaba esta iglesia, realizada en estilo románico, mucho menos espacio que la actual Catedral, de forma que la cabecera no ocuparía más allá del actual crucero. Pero pronto se vió que aquel edificio resultaba pequeño por el auge que iba adquiriendo la ciudad, tanto por su carácter comercial, como porque Alfonso VIII habia decidido instalar en ella la corte. Así, las ceremonias que por el nuevo carácter de la ciudad se celebraban en ella, quedaban empobrecidas por resultar pequeño el marco, como quedó plenamente de manifiesto con la celebración del matrimonio entre el santo rey Fernando III y doña Blanca de Suabia, siendo el celebrante el obispo don Mauricio.

Ante esta situación, el obispo don Mauricio y el rey Fernando III decidieron emprender la construcción de un nuevo edificio que sustituyera a aquel que ya resultaba insuficiente.

Comenzó pues la obra con la tradicional colocación de la primera piedra, ceremonia que tuvo lugar el día 20 de julio del año 1221, emprendiéndose entonces la construcción de un edificio cuya tipología era completamente extraña a lo hasta entonces construido en las tierras castellanas, pero no asi para don Mauricio, que hombre de gran cultura, estaba al tanto de las novedades artisticas que imperaban más allá de los Pirineos, pues por ejemplo habia estudiado Teologia en París, había asistido al IV Concilio de Letrán, y había acudido a Alemania a la cabeza de la embajada que trataría el matrimonio de Fernando III con Blanca de Suabia.

Las obras discurrieron rápidamente bajo las directrices y los planos de un maestro que sin duda era francés, y más posiblemente de contactos con la arquitectura normanda. La rapidez de las obras lo demuestra el hecho de que en el año 1238 moría el obispo don Mauricio y era enterrado en el actual presbiterio. A mediados del siglo XIII debió de hacerse cargo de las obras el maestro Enrique, también francés, pero éste con mayores relaciones con la arquitectura de Champaña, y que también fue maestro mayor de la Catedral de León desde 1255. Fue el maestro Enrique arquitecto fiel al primer proyecto, y no alteró los planos, habiendo realizado la nave del crucero y las portadas de éste, debiendo de estar concluida esta parte del edificio cuando se realizó la consagración de la Catedral, en 1260.

En 1277 murió el maestro Enrique, continuando la dirección de las obras el maestro Juan Pérez, también fiel al primer proyecto y que debió realizar la zona de los pies del edificio y una parte de la fachada principal de la iglesia, asi como el claustro, debiendo quedar finalizadas las obras entre los finales del siglo XIV y los principios del siglo XV.
A partir de este momento comenzaron diversas actuaciones para mejorar el conjunto, siendo esencial la intervención del obispo don Alonso de Cartagena, que gran viajero, estaba al tanto de las corrientes artísticas de la Europa de su tiempo, y que conoció el arte alemán al haber asistido al Concilio de Basilea (1433). Al regreso de éste, fue consagrado en 1435 arzobispo de la sede burgalesa, y es posible que ante las novedades recién vistas hiciera llamar a un arquitecto alemán, Juán de Colonia, para realizar el remate de las torres de la fachada principal, labor que tuvo su comienzo en 1442 y se concluyó en 1458. Las flechas de estas torres son sin duda de lo más vistoso del exterior de la Catedral, siendo semejantes a las del sur de Alemania.

Cuando finalizaron las obras de estas torres, el entonces prelado de la sede, don Luis de Acuña, encargó al mismo maestro la construcción de un cimborrio sobre el crucero, obra que se vino abajo en 1539 . La restauración comenzó enseguida, siendo el encargado de llevarla a cabo Juán de Vallejo, quien dio por finalizadas las obras en 1576, habiendo logrado hacer un cimborrio aún más grandioso que el anterior, y que hacia del interior una maravilla por su bóveda estrellada calada.

Estructuralmente el edificio presenta una planta de cruz latina, con tres naves, girola con capillas radiales y nave de crucero marcada en planta y en altura, aunque esta estructura fue paulatinamente alterada para transformar o añadir capillas.

En la cabecera se ha señalado la semejanza con la arquitectura gótica de Normandía, y en concreto con la catedral de Coutances, con la que efectivamente tiene interesantes analogias, pero que debió de comenzar sus obras más o menos al tiempo que la catedral de Burgos, por lo que no puede hablarse de una influen. cia directa de la catedral francesa en la española. Lo que ciertamente debió de ocurrir, es que el anónimo primer maestro de la Catedral tendría contactos con el arte normando, y habría anotado en su álbum soluciones y dibujos de elementos vistos en aquella zona que fueron igualmente aprovechados para la Catedral de Coutances.

Entre estos elementos destaca especialmente el tipo de abovedamiento de los tramos de la girola, pues aparte de la solución tan corriente, dada la planta trapezoidal de estos tramos, de descoyuntar los nervios para situar en el centro de la bóveda la clave, hay un quinto nervio que une esa clave con la del arco formero de la entrada de la capilla radial correspondiente. E igualmente también es semejante a Coutances el abovedamiento original del presbiterio, a base de nervios de cruceria sencilla sobre planta barlonga, y una ligadura longitudinal que une todas las bóvedas de este tramo. 


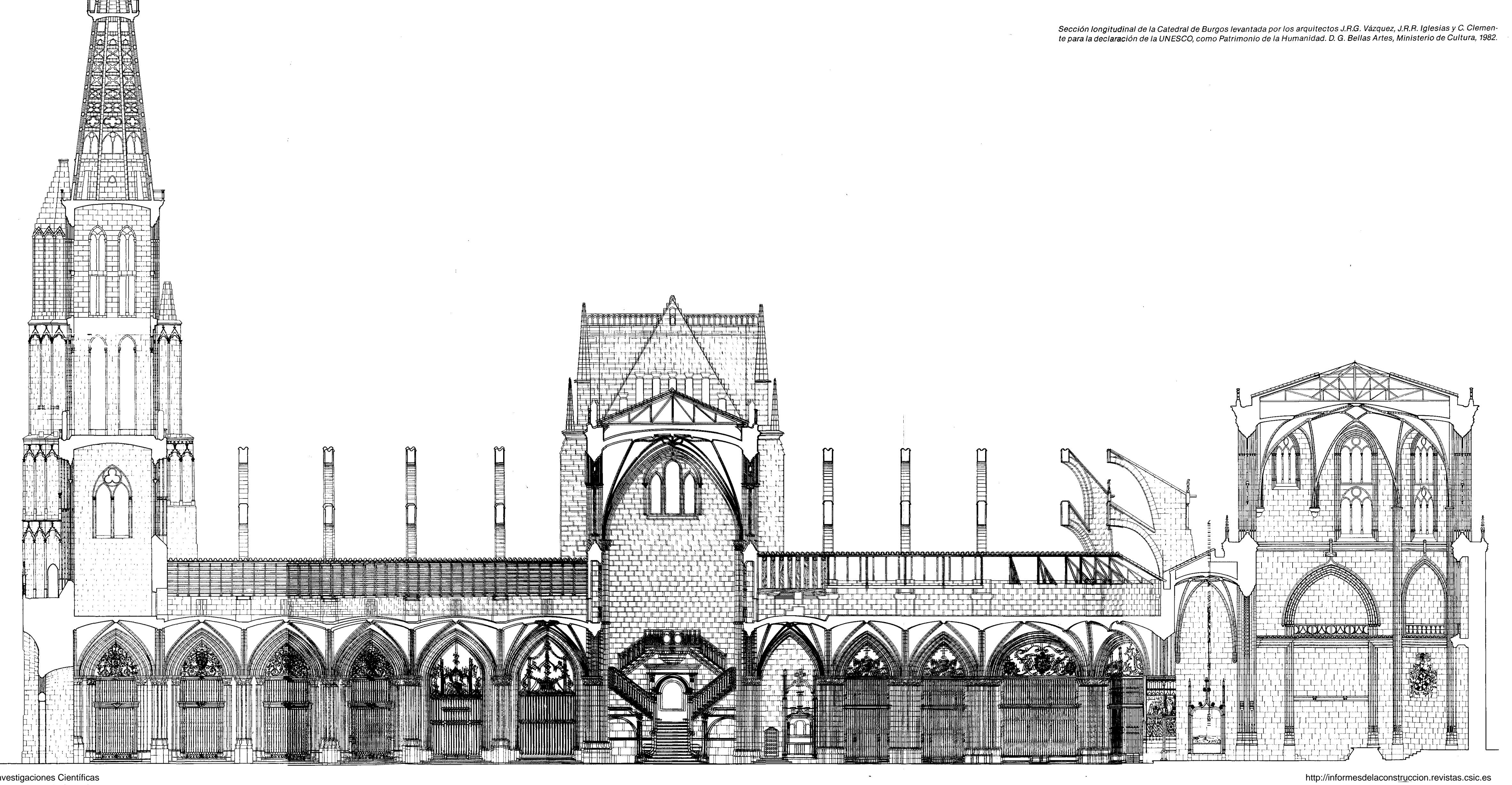


Sin embargo, en el alzado las analogías no son con la Catedral de Coutances, sino más bien con la de Bourges. Con ella puede señalarse especialmente el parecido en el diseño del triforio, a base de un ancho arco apuntado que contiene en su interior una rica traceria en la parte superior, a base de un juego de círculos con trifolios y cuatrifolios, bajo la que hay una serie de arquitos polilobulados.

En los pilares, formados por un núcleo circular con columnillas adosadas, ha sido también señalada la semejanza con Bourges, pero sin embargo, este tipo se desarrolla en Francia, de una forma corriente, durante el siglo XIII, siendo común también a otras catedrales como las de Reims o Amiens. Sin embargo si que es cierto que en estas últimas catedrales las columnillas son cuatro, en tanto que en Burgos, al igual que en Bourges, son ocho.

Las ventanas responden también al modelo que se desarrolló en el gótico francés de la primera mitad del siglo XIII, a base de un arco dividido en otros dos por una columnilla sobre los cuales se dispone una rosa.

Exteriormente en la Catedral llama la atención los grandes espacios despejados que la rodean, al menos en las zonas que se precisa una buena perspectiva. Ya desde un primer momento fue ésta una ambición tanto de las autoridades eclesiásticas como de las municipales, y asi, en el siglo XV, al poco de concluirse la construcción, se despejaron de casas los espacios situados ante la fachada principal y ante la del Sarmental, aunque no fue hasta el siglo XIX cuando la Catedral logró la limpieza de edificios que presenta en la actualidad, y que tanto la enriquece.

De esta forma pueden admirarse hoy en día perfectamente las portadas, que son otro de los puntos interesantes del edificio, ya que también permiten rastrear el origen de sus constructores.

La fachada principal sigue el esquema general de las fachadas de las catedrales góticas, con tres portadas en el primer cuerpo, un par de ventanas flanqueando un rosetón en el segundo y por encima la galería de los reyes, en este caso con un gran desarrollo en altura, de manera que forma un tercer cuerpo, que es flanqueado por las torres que rematan en las caladas agujas del siglo XV.

Pero esta fachada sufrió una gran transformación en el siglo XVIII debido al estado ruinoso que presentaba, con las esculturas en situación penosa a causa del agua y de las heladas, de forma que se desmontó y se construyó una puerta de estilo neoclásico, que contrasta vivamente con el esquema general del edificio.
La portada más antigua es la del Sarmental, que se realizó en torno al año 1240 y está ligada a la actividad del maestro Enrique, quien sin duda trajo consigo algún equipo de canteros y escultores que realizaron una portada y fachada, que en lo arquitectónico y en lo decorativo sigue en buena parte los esquemas del gótico champañés, y de una manera especial el de la Catedral de Reims, como es muestra el rosetón, muy semejante al de la fachada meridional del crucero de esa Catedral francesa.

La portada propiamente dicha tiene representada en el tímpano una iconografía un tanto ya pasada de moda para la fecha en que se realizó, pues muestra a Cristo Glorioso, rodeado por los símbolos de los Evangelistas a los que se ve un poco más atrás, sentados cada uno ante un pupitre escribiendo el Evangelio. En el dintel aparacen sentados los Apóstoles, y en las arquivoltas figuran los Ancianos del Apocalipsis y ángeles. Bastante por encima de ella se abre el rosetón mencionado, y por encima de él una galería que cobija las imágenes de Cristo y ángeles que portan cirios.

La Catedral tiene otras dos portadas más, de las que la del brazo norte del crucero, la llamada de la Coronería es tal vez la más llamativa por la solución que hubo que darle en la parte interior del edificio.

Al estar apoyada la Catedral contra una colina, resultó que la entrada quedaba a un nivel mucho más alto que el del piso del edificio. La solución se había resuelto con una escalera que hubo de demolerse a principios del siglo XVI, encargándose entonces, en 1519, a Diego de Siloe la construcción de una nueva, que debió de terminarse en 1525.

La escalera construida por este maestro es la llamada "Escalera Dorada", sin duda una de las joyas arquitectónicas de la Catedral, por la estructura que dio para solucionar el problema absorbiendo el menor espacio posible. El esquema puede estar inspirado en la escalera del Belvedere del Vaticano, pues como ella, arran. ca con un corto tramo en sentido vertical a la fachada que se abre en dos ramas hasta llegar a las paredes laterales del brazo del crucero, donde invierten el camino hasta reunirse de nuevo ante la puerta, en lo alto de la escalera. La original estructura se completa con una rica decoración de grutescos y una barandilla rea. lizada por el maestro Hilario, de origen francés y que la concluyó en 1526.

Exteriormente la portada presenta el tema del Juicio Final, obra de la segunda mitad del siglo XIII, mientras que la puerta de acceso, cobijada dentro de este conjunto gótico, responde al estilo manierista. 
La última portada, la de la Pellejeria, está situada en el muro oriental del brazo norte del crucero, siendo construida en el año 1516 para salvar el obstáculo que significaba la Puerta de la Coroneria, pues se realizó al nivel de la Catedral. Obra encargada por el arzobispo don Juán Rodriguez de Fonseca fue realizada por Francisco Colonia y responde al primer estilo renacentista en Castilla.

En el conjunto de la Catedral destaca de una forma im. presionante la Capilla del Condestable. En el exterior por su gran volumen y por la corona de pináculos que lo rematan y en el interior por su gran espacialidad y su rica decoración.

Está situada en la prolongación de la capilla radial del centro de la girola, y por lo tanto en el eje de la Cate- dral. Fue encargada a Simón de Colonia en el año 1486, por el Condestable de Castilla don Pedro Fernández de Velasco y su mujer, doña Mencia de Mendoza, terminando las obras en 1494, aunque la actividad decorativa aún se prolongó durante el primer tercio del siglo XVI. El conjunto, que se desarrolla sobre una planta poligonal, cubierta con una bóveda estrellada con su parte central calada, es uno de los más impresionantes del arte hispanoflamenco por la exuberante decoración que posee, y que se completa con el magnifico retablo principal dedicado al tema de la Presentación del Niño en el Templo y Purificación de la Virgen, realizado en el plano escultórico por Felipe Vigarny y Diego de Siloe y policromado por León Picardo. Complemento artístico de este retablo es el sepulcro de los Condestables, esculpido en mármol de Carrara por Felipe Vigarny, donde dejó una muestra palpable de su exquisito tratamiento de la escultura.

\section{publicación del ICCET/CSIC}

\section{ACUEDUCTOS ROMANOS EN ESPAÑA Carlos Fernández Casado \\ Prof. Dr. Ing. de Caminos, Canales y Puertos}

Esta publicación se compone de una serie de articulos, publicados en la Revista "Informes de la Construcción", en los cuales se hace un análisis de los acueductos romanos que existen en España y el balance de las condiciones de conservación en que se encuentra cada uno de ellos, incluyendo referencias históricas y literarias. Se ha ilustrado con la reproducción de la valiosa documentación gráfica que posee el prestigioso autor.

Un volumen encuadernado en couché, a dos colores, de $21 \times 27$ centimetros, compuesto de 238 páginas, numerosos grabados, dibujos, fotos en blanco y negro y figuras de linea.

Precio: España, 1.500 ptas., 21 \$ USA.

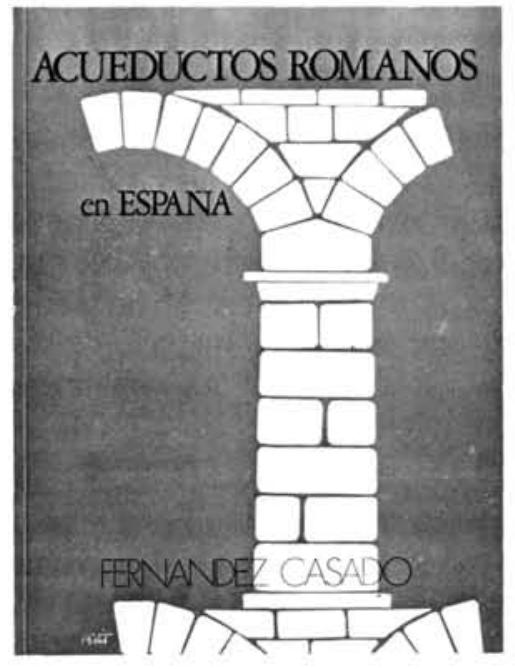

